\title{
Analisis Finansial Usaha Pembesaran Ikan Nila dalam Keramba "H. Jam'an" Di Desa Sungai Hanyar Kecamatan Banua Lawas Kabupaten Tabalong
}

\author{
(Business Financial Analysis Enlargement Tilapia in The Cage " H. Jam'an" \\ at Sungai Hanyar Village Banua Lawas District Tabalong Regency)
}

\author{
Miranda Romaully Br. Sitanggang ${ }^{1)}$, Mahdalena ${ }^{2)}$ \& Norhasanah $^{3)}$ \\ Program Studi Agribisnis, Sekolah Tinggi Ilmu Pertanian Amuntai \\ ${ }^{1)}$ miranda.rsd2203@gmail.com \\ 2)dalena.stiper@gmail.com \\ ${ }^{3)}$ sanah@gmail.com
}

\begin{abstract}
ABSTRAK
Penelitian ini bertujuan untuk (i) mengetahui besarnya Net Present Value (NPV) dan Internal Rate of Return (IRR) usaha pembesaran ikan nila dalam keramba di Desa Sungai Hanyar (ii) mengetahui lama waktu yang diperlukan (Pay Back Priode) untuk mengembalikan modal usaha pembesaran ikan nila dalam keramba (iii) mengetahui titik impas (Break Event Point) pada usaha pembesaran ikan nila dalam keramba. Metode yang digunakan adalah metode deskriptif. Desain penelitian adalah desain studi kasus dan penelitian lapangan. Analisis data yang digunakan adalah finansial dan untuk membuat studi kelayakan adalah analisis keuangan dan untuk membuat studi kasus penelitian lapangan. Analisis data menggunakan NPV, IRR <, da PBP. Total biaya dalam usaha pemeliharaan ikan nila Rp. 55.210.012, - per tahun, sedangkan pendapatan sebesar Rp. 153.250.000, - per tahun dan pendapatan dalam bisnis pemeliharaan ikan nila Rp. 101.836.000 million, - per tahun. Pada usaha pemeliharaan ikan nila H.Jam'an di Sungai Hanyar Banua Lawas Kabupaten Tabalong berdasarkan analisis kelayakan investasi Net Net Value Value (NPV) NPV sebesar Rp. 220.353.136 diketahui, - Hasil penelitian menunjukkan NPV>0, berarti upaya pembesaran nila H.jam'an layak / dilanjutkan. Berdasarkan metode perhitungan Retrun secara internal menghasilkan $87 \%$ dan biaya kesempatan sosial modal (SOCC) sebesar 18\% ini berarti IRR> SOCC, dengan demikian usaha pembesaran ikan nila H.Jam'an di Desa Sungai Hanyar Kecamatan Banua Lawas Kabupaten Tabalong layak untuk dibudidayakan / dilanjutkan. Hasil analisis kelayakan berdasarkan payback period investment (PBP) pada bisnis pemeliharaan ikan nila H. Jam'an di Sungai Hanyar Banua Lawas Kecamatan Tabalong 1 tahun 11 bulan 28 hari sudah mendapatkan pengembalian investasi.
\end{abstract}

Kata kunci: Ikan, nila, pembesaran, analisis, pendapatan.

\section{ABSTRACT}

This study aims to (i) find out the magnitude of the Net Present Value (NPV) and Internal Rate of Return (IRR) efforts to enlarge tilapia in cages in Sungai Hanyar Village (ii) to know the Pay Back Prize to restore business capital enlargement of tilapia in cages (iv) knowing the break-even point (Break Event Point) in an effort to enlarge tilapia in cages. The method used is descriptive method. The research design is case study design and field research. Analysis of the data used is financial and to make a feasibility study is financial analysis and to make a case study of field research. Data analysis using NPV, IRR <, and PBP. The total cost of maintaining tilapia is Rp. 55,210,012, - per year, while income is Rp. 153,250,000 per year and income in the tilapia fish maintenance business Rp. 101,836,000 million, - per year. In the maintenance business of tilapia H. Jam'an in Sungai Hanyar Banua Lawas Tabalong Regency based on an analysis of the investment feasibility of Net Net Value Value (NPV) of Rp. 220,353,136 is known. - The results of the study show NPV> 0, meaning that the effort to enlarge H.jam'an indigo is feasible / continued. Based on the Retrun calculation method internally produces $87 \%$ and the social opportunity cost of capital (SOCC) of 18\% means IRR> SOCC, thus the business of enlarging H.Jam'an tilapia in Sungai Hanyar Village, Banua Lawas District, Tabalong Regency is feasible to be cultivated / next. The results of the feasibility analysis based on the payback period investment (PBP) in the maintenance business of H. Jam'an tilapia in 
Sungai Hanyar Banua Lawas, District of Tabalong 1 year 11 months 28 days have received a return on investment.

Keywords: Fish, indigo, enlargement, analysis, income.

\section{PENDAHULUAN}

Usaha perikanan merupakan suatu kegiatan usaha ekonomis, dimana manusia mengusahakan, mengelola dan mengendalikan sumberdaya hayati perikanan untuk mendapatkan keuntungan sebesarbesarnya demi meningkatkan kesejahteraan dan pendapatan pembudidaya. Pembangunan usaha perikanan diarahkan untuk memperbaiki usaha budidaya perikanan yang sederhana menjadi budidaya perikanan yang maju. Ikan air tawar yang paling sering di budidayakan salah satunya adalah ikan nila, jenis ikan ini ialah yang diintroduksi dari afrika, tepatnya di wilayah afrika adegan timur, di tahun 1969, dan ikan ini sudah membuahkan pemeliharaan yang paling populer di keramba-keramba air tawar di tiap-tiap wilayah di indonesia, nila memiliki pangsa pasar yang cukup besar, baik di dalam negeri maupun di luar negeri dengan nilai jual cukup tinggi. Budidaya ikan nila relatif mudah karena mudah di pelihara.

Menurut Rohmawati (2010), bahwa berdasarkan aspek pasar, teknis, aspek sosial dan manjemen, pengembangan usaha ikan nila air tawar Arifin Fish Desa Ciluar, Kecamatan Bogor Utara, Kota Bogor layak dijalankan. Berdasarkan aspek finansial pengembangan usaha ikan nila air tawar Arifin Fish layak dijalankan dengan nilai NPV yang diperoleh sebesar Rp 2.039.639.749,00 berarti bahwa investasi yang ditanam pada 10 tahun yang akan datang dapat memberikan keuntungan bersih sebesar Rp 2.039.639.749,00 ; Net B/C yang diperoleh sebesar 4,08 artinya setiap $\mathrm{Rp} 1,00$ investasi bersih yang dikeluarkan pada tahun ke 10 akan memberikan keuntungan sebesar Rp 4,08 ; dengan IRR sebesar 60\% menunjukan bahwa rencana pengembangan ini layak dan mampu untuk mengembalikan modal dalam tingkat bunga sebesar 10,25\% serta Payback Period sebesar 2,03 tahun.

Penelitian ini bertujuan untuk (i) mengetahui besarnya Net Present Value (NPV) dan Internal Rate of Return (IRR) usaha pembesaran ikan nila dalam keramba di Desa Sungai Hanyar (ii) mengetahui lama waktu yang diperlukan (Pay Back Priode) untuk mengembalikan modal usaha pembesaran ikan nila dalam keramba (iii) mengetahui titik impas (Break Event Point) pada usaha pembesaran ikan nila dalam keramba.

\section{METODE PENELITIAN}

\section{Tempat dan Waktu Penelitian}

Penelitian ini dilaksanakan pada usaha “Budidaya Ikan Nila H.Jam'an” Desa Sungai Hanyar RT 02 Kecamatan Banua Lawas Kabupaten Tabalong. Pemilihan Usaha Budidaya H. Jam'an, karena usaha beliau cukup besar. Penelitian di laksanakan dari bulan April 2015 sampai selesai.

\section{Jenis Dan Sumber Data}

Jenis penelitian, dan dalam penelitian ini data yang dikumpulkan terdiri dari data primer dan data sekunder. Data Primer diperoleh melalui peninjauan langsung terhadap kondisi usaha pembesaran ikan nila dan wawancara dengan petani/pembudidaya ikan nila di Desa Sungai Hanyar. Sedangkan data sekunder diperoleh dari berbagai instansi yang terkait ataupun literatur serta melalui berbagai media yang berhubungan dengan penelitian ini, seperti internet, buku, dan skripsi terdahulu.

\section{Metode Pengumpulan Data}

Metode pengumpulan data dalam penelitian ini adalah menggunakan metode studi kasus. Oleh karena itu perlu digunakan metode pengumpulan data yang baik dan 
cocok. Penelitian ini menggunakan metode studi kasus yaitu kepada Usaha "Budidaya Ikan Nila H. Jam'an” di Desa Sungai Hanyar Kecamatan Banua Lawas Kabupaten Tabalong. Pihak yang menjadi responden dalam penelitian ini adalah $\mathrm{H}$. Jam'an atau yang bersangkutan. Penelitian ini merupakan penelitian kualitatif dan kuantitatif. Data diperoleh dari wawancara dengan responden yaitu menggunakan daftar pertanyaan. Responden dalam penelitian ini dipilih secara sengaja. Responden terdiri dari pihak H.Jam'an / yang bersangkutan budidaya ikan nila di Desa Sungai Hanyar Kecamatan Banua Lawas.

\section{Analisis Data}

Tujuan pertama yaitu untuk mengetahui jumlah biaya usaha yang dikeluarkan pada usaha pembesaran ikan nila rumus yang digunakan adalah sebagai berikut:

\section{Biaya Tetap}

Biaya tetap adalah jenis-jenis biaya yang selama satu periode akan tetap jumlahnya. Biaya tetap sering juga disebut biaya kepemilikan. Biaya ini tidak tergantung pada produk yang dihasilkan dan bekerja atau tidaknya mesin serta besarnya relatif tetap.

\section{Biaya Variabel}

Biaya tidak tetap atau biaya variabel adalah biaya-biaya yang dikeluarkan pada saat alat dan mesin beroprasi dan jumlahnya bergantung pada jam pemakaiannya (kasim, 2004).

\section{Biaya Total}

Biaya total/biaya operasional merupakan penjumlahan antara total biaya tetap dengan total biaya variabel, nilainya ditentukan dalam jumlah biaya per tahun.

Untuk mengetahui Tujuan kedua digunakan rumus sebagai berikut:

Net Present Value (NPV)
Rumus yang digunakan untuk menghitung Net Present Value (NPV) adalah sebagai berikut:

$$
\mathrm{NPV}=\sum_{\mathrm{i}=1}^{\mathrm{n}} \frac{\mathrm{CFt}}{(1+\mathrm{K})^{\mathrm{t}}}
$$

Dimana:

$$
\begin{aligned}
& \text { NPV = Net Present Value }(\mathrm{Rp}) \\
& \mathrm{CFt}=\text { Aliran kas pertahun pada } \\
& \text { periode } \mathrm{t} \\
& 1_{0}=\text { Investasi awal pada tahun } 0 \\
& \mathrm{~K}=\text { Suku bunga (Discont rate) } \\
& \mathrm{i} \quad=0,1,2,3, \ldots \ldots ., \mathrm{n} \\
& \text { Jika NPV } \geq 0 \text {, maka usaha layak }
\end{aligned}
$$

$$
\begin{aligned}
& \text { Internal Rate of Return (IRR) } \\
& I R R=i_{1}+\frac{N_{1}}{\left(N P V_{1}-N P V_{2}\right)} \cdot\left(i_{2}-i_{1}\right)
\end{aligned}
$$

Di mana:

$\mathrm{I}_{1}$ : Tingkat discunt rate yang menghasilkan $\mathrm{NPV}_{1}$

$\mathrm{I}_{2}$ : Tingkat discount rate yang menghasilkan $\mathrm{NPV}_{2}$

Dengan kata laain:

Bila IRR > discount rate (tingkat suku bunga bank) maka usaha tersebut layak di usahakan, dan sebaliknya

Bila IRR < discont rate (tingkat suku bunga bank) maka usaha tersebut tidak layak di usahakan.

\section{Pay Back Period (PBP)}

Rumus:

$$
\begin{aligned}
& \sum_{i=1}^{n} l i-\bar{\sum} \text { Bicp-1 } \\
& \hline \text { PBP }=T p-1+\quad B p
\end{aligned}
$$

Dimana:

PBP : Pay Back Period

Tp-1 : Tahun sebelum terdapat PBP 
di discount

Ii : Jumlah investasi yang telah

Bicp : Jumlah benefit di discount sebelum PBP

Bp : Jumlah benefit pada PBP

Kriteria pay back period ini makin cepat modal kembali makin baik,dengan kata lain:

Jika pay back period < maksimum waktu yang disyaratkan maka diterima.

Jika pay back period > maksimum waktu yang disyaratkan maka ditolak. (Ibrahim, 1998).

Untuk mengetahui Tujuan ketiga digunakan rumus sebagai berikut:

\section{Break Event Point (BEP)}

digunakan rumus atau formula sebagai berikut:

Sumber : Ibrahim (1998)

Total Pendapatan :

$$
\operatorname{BEP}(\mathbf{R p})=\frac{\text { Total Biaya Tetap }}{\left(1-\begin{array}{l}
\text { Biaya Variabel/unit } \\
\text { Harga Jual }
\end{array}\right)}
$$

Jumlah yang diproduksi :

$$
\operatorname{BEP}(Q)=\frac{\text { Total Biaya Tetap }}{(\text { Harga Jual }- \text { Biaya Variabel } / \text { Unit })}
$$

\section{HASIL DAN PEMBAHASAN}

\section{Analisis Kelayakan Finansial Usaha Pembesaran Ikan Nila}

\section{Biaya Investasi}

Biaya Investasi merupakan biaya awal yang dikeluarkan untuk melakukan kegiatan usaha budidaya ikan nila ini. Komponen ini terdiri dari pengadaan peralatan. Alat transportasi, dan sebagainya yang berhubungan dengan kegiatan produksi. Untuk lebih jelasnya dapat dilihat pada tabel berikut

Tabel 1. Biaya tetap pada usaha budidaya ikan nila dalam keramba

\begin{tabular}{ccc}
\hline No & Uraian & Total Biaya \\
\cline { 3 - 3 } & & Pertahun $(\mathrm{Rp})$ \\
\hline 1 & Biaya Administrasi & 120.000 \\
3 & Pajak & 700.000 \\
4 & Biaya Pemeliharan & 150.000 \\
& Penyusutan investasi & 18.774 .000 \\
\hline
\end{tabular}

Tabel 2. Biaya variabel pada usaha budidaya ikan nila dalam keramba

\begin{tabular}{ccccccc}
\hline \multirow{2}{*}{ No. } & \multirow{2}{*}{ Nama Barang } & \multicolumn{5}{c}{ Total Biaya Per Tahun (Rp) } \\
\cline { 3 - 7 } & & 2010 & 2011 & 2012 & 2013 & 2014 \\
\hline 1 & Benih Ikan & 2.375 .000 & 5.775 .000 & 9.500 .000 & 12.875 .000 & 23.500 .000 \\
2 & Pakan & 3.500 .000 & 13.000 .000 & 24.850 .000 & 36.375 .000 & 57.300 .000 \\
3 & Upah Panen & 1.025 .000 & 4.000 .000 & 5.350 .000 & 6.400 .000 & 12.140 .000 \\
4 & Upah Tenaga angkut & 600.000 & 6.000 .000 & 10.250 .000 & 12.875 .000 & 23.500 .000 \\
\hline \multicolumn{2}{c}{ Jumlah } & 7.500 .000 & 28.775 .000 & 49.950 .000 & 68.525 .000 & 116.440 .000 \\
\hline
\end{tabular}

Tabel 3. Total biaya operasional usaha "Budidaya Ikan Nila H. Jam'an" Desa Sungai Hanyar Kecamatan Banua Lawas Kabupaten Tabalong

\begin{tabular}{clccccc}
\hline \multirow{2}{*}{ No } & \multirow{2}{*}{ Uraian } & \multicolumn{5}{c}{ Tahun } \\
\cline { 2 - 6 } & & 2010 & 2011 & 2012 & 2013 & 2014 \\
\hline 1 & Biaya Variabel & 7.500 .000 & 28.775 .000 & 49.950 .000 & 68.525 .000 & 116.440 .000 \\
2 & Biaya Tetap & 970.000 & 970.000 & 970.000 & 970.000 & 970.000
\end{tabular}


Miranda Romaully B.R. Sitanggang, Mahdalena \& Norhasanah, Analisis finansial...

\begin{tabular}{cccccc} 
Jumlah $(\mathrm{Rp})$ & 8.470 .000 & 29.745 .000 & 50.920 .000 & 69.495 .000 & 117.410 .000 \\
\hline Rata -rata & & 55.210 .012 & \\
\hline
\end{tabular}

Tabel 4. Total penjualan/penerimaan usaha “Budidaya Ikan Nila H.Jam’an” di Desa Sungai Hanyar Kecamatan Banua Lawas Kabupaten Tabalong

\begin{tabular}{ccccccc}
\hline \multirow{2}{*}{ No } & \multirow{5}{*}{ Uraian } & \multicolumn{4}{c}{ Tahun } \\
& & \multicolumn{5}{c}{ Penjualan(Rp) } \\
\cline { 3 - 6 } & & 2010 & 2011 & 2012 & 2013 & 2014 \\
\hline 1 & Ikan Nila & 88.000 .000 & 105.250 .000 & 125.750 .000 & 150.750 .000 & 296.500 .000 \\
& Jumlah(Rp) & 88.000 .000 & 105.250 .000 & 125.750 .000 & 150.750 .000 & 296.500 .000 \\
\hline \multicolumn{3}{r}{ Rata -rata } & & 153.250 .000 & \\
\hline
\end{tabular}

Tabel 5. Hasil pendapatan usaha "Budidaya Ikan Nila H.Jam'an" di Desa Sungai Hanyar Kecamatan Banua Lawas Kabupaten Tabalong

\begin{tabular}{ccccccc}
\hline & & \multicolumn{5}{c}{ Tahun } \\
\cline { 3 - 6 } No & Keterangan & \multirow{2}{*}{2010} & 2011 & 2012 & 2013 & 2014 \\
& & & & & \multirow{2}{*}{20180.060 .000} \\
\hline 1 & Ikan Nila & 97.530 .000 & 75.505 .000 & 74.830 .000 & 81.255 .000 & 1800 \\
& Rata -rata & & & 101.836 .000 & & \\
\hline
\end{tabular}

\section{Analisis Kelayakan Investasi}

Tabel 6. Net Present Value (NPV)

\begin{tabular}{|c|c|c|c|c|c|c|c|}
\hline \multirow{2}{*}{ No } & \multirow{2}{*}{ Uraian } & \multicolumn{6}{|c|}{ Tahun } \\
\hline & & 0 & 1 & 2 & 3 & 4 & 5 \\
\hline 1 & Penerimaan & - & 88.000 .000 & 105.250 .000 & 125.750 .000 & 150.750 .000 & 296.500 .000 \\
\hline 2 & Biaya investasi & 74.000 .000 & - & - & - & - & - \\
\hline 3 & Biaya operasi & - & 8.470 .000 & 29.745 .000 & 50.920 .000 & 69.495 .000 & 117.410 .000 \\
\hline 4 & Total cost & - & 8.470 .000 & 29.745 .000 & 50.920 .000 & 69.495 .000 & 117.410 .000 \\
\hline 5 & Net Benefit & -74.000 .000 & 87.991 .530 & 75.505 .000 & 74.830 .000 & 81.255 .000 & 179.090 .000 \\
\hline 6 & D.F $18 \%$ & 1,000 & 0,847 & 0,718 & 0,607 & 0,516 & 0,437 \\
\hline 7 & Present Value & -74.000 .000 & 74.528 .826 & 54.212 .590 & 45.421 .810 & 41.927 .580 & 78.262 .330 \\
\hline 8 & NPV - & & & & & & \\
\hline & Total P.V & & & 220.353 .136 & & & \\
\hline
\end{tabular}

Tabel 7. Internal Rate of Return (IRR)

\begin{tabular}{cccccccc}
\hline \multirow{2}{*}{ No } & Uraian & \multicolumn{7}{c}{ Tahun } \\
\cline { 3 - 7 } & & 0 & 1 & 2 & 3 & 4 & 5 \\
\hline 1 & Net Benefit & -74.000 .000 & 47.030 .000 & 26.025 .000 & 46.617 .000 & 28.042 .000 & 179.090 .000 \\
2 & D.F 18\% & 1,000 & 0,847 & 0,718 & 0,609 & 0,516 & 0,437 \\
3 & Present Value & -74.000 .000 & 74.528 .826 & 54.212 .590 & 45.421 .810 & 41.927 .580 & 78.262 .330 \\
4 & D.F 33\% & - & 0,5263 & 0,2769 & 0,1454 & 0,0765 & 0,0406 \\
5 & Present Value & -74.000 .000 & 39.224 .521 & 15.011 .466 & 6.604 .331 & 3.207 .459 & 3.177 .450 \\
6 & NPV1 & & & 220.353 .136 & & & \\
7 & NPV2 & & -6.774 .773 & & \\
\hline
\end{tabular}


Tabel 8. Pay Back Period (PBP)

\begin{tabular}{llcccccc}
\hline \multirow{2}{*}{ No Uraian } & \multicolumn{7}{c}{ Tahun } \\
\cline { 2 - 7 } & 0 & 1 & 2 & 3 & 4 & 5 \\
\hline 1 & Penerimaan & - & 88.000 .000 & 105.250 .000 & 125.750 .000 & 150.750 .000 & 296.500 .000 \\
2 & Biaya Investasi & 74.000 .000 & - & - & -1 & - & - \\
& Biaya & & & & & & \\
3 & Operasional & - & 26.274 .970 & 47.549 .970 & 68.724 .970 & 87.299 .970 & 135.214 .970 \\
4 & B Nefit & - & 88.000 .000 & 105.250 .000 & 125.750 .000 & 150.750 .000 & 296.500 .000 \\
5 & D.F 18\% & 1,000 & 0,847 & 0,718 & 0,609 & 0,516 & 0,437 \\
6 & T. sebelum PBP & 74.000 .000 & - & - & - & - & - \\
7 & OM & - & 22.254 .899 & 34.140 .879 & 41.853 .507 & 45.046 .785 & 59.088 .942 \\
8 & B & - & 74.536 .500 & 75.569 .500 & 76.581 .750 & 77.787 .000 & 129.570 .500 \\
\hline
\end{tabular}

Tabel 9. Break Event Point (BEP)

\begin{tabular}{ccccccc}
\hline \multirow{2}{*}{ No } & \multirow{2}{*}{ Uraian } & \multicolumn{5}{c}{ Tahun } \\
\cline { 2 - 6 } & & 1 & 2 & 3 & 4 & 5 \\
\hline 1 & Total biaya tetap(Rp) & 18.774 .000 & 18.774 .000 & 18.774 .000 & 18.774 .000 & 18.774 .000 \\
2 & Biaya Variabel(Rp) & 7.500 .000 & 28.775 .000 & 49.950 .000 & 68.525 .000 & 116.440 .000 \\
3 & Penerimaan(Rp) & 88.000 .000 & 105.250 .000 & 125.750 .000 & 150.750 .000 & 296.500 .000 \\
4 & Harga Jual Produk(kg) & 30.000 & 30.000 & 30.000 & 30.000 & 30.000 \\
5 & & & & & \\
& Jumlah Produksi (Q) & 750.000 & 750.000 & 750.000 & 750.000 & 750.000 \\
6 & Biaya Variabel/unit(ekor & 13.000 & 13.000 & 13.000 & 13.000 & 13.000 \\
7 & BEP(Rp) & 31.130 .393 & 31.130 .393 & 31.130 .393 & 31.130 .393 & 31.130 .393 \\
8 & BEP(Q) & 1.104 .353 & 1.104 .353 & 1.104 .353 & 1.104 .353 & 1.104 .353 \\
\hline
\end{tabular}

Tabel diatas menunjukkan bahwa keadaan Bep (Rp) setiap tahun berada Rp. 31.130.393,-. keadaan dimana pada saat pendapatan mencapai jumlah $\mathrm{Rp}$. 31.130.393,- Usaha Budidaya pembesaran ikan nila H.Jam'an tidak mengalami kerugian.Sedangkan untuk BEP(Q) setiap tahun berada pada 1.104.353/tahun.

\section{KESIMPULAN}

Analisis Finansial metode Net Present Value NPV) diketahui NPV sebesar Rp. 220.353.136. Hasil menunjukkkan bahwa NPV > 0, ini berarti usaha Budidaya Pembesaran Ikan Nila H. Jam'an layak diusahakan. Analisis Finansial berdasarkan metode internal rate of retrun menghasilkan nilai sebesar $87 \%$ dan social opportuny cost of capital (SOCC) sebesar $18 \%$ ini berarti IRR > SOCC, dengan demikian usaha budidaya pembesaran ikan nila H. Jam'an di Desa Sungai Hanyar Kecamatan Banua Lawas Kabupaten Tabalong Layak untuk di usahakan/dilanjutkan. Analisis finansial berdasarkan pay Back period (PBP) pada usaha budidaya ikan nila H. Jam'an di Desa Sungai Hanyar Kecamatan Banua Lawas Kabupaten Tabalong adalah 1 Tahun 11 bulan 28 hari sudah mendapatkan pengambalian investasi. Berdasarkan Break Event Point Break Even Point (BEP) di peroleh BEP (Rp) berada pada saat pendapatan Rp. 31.130.393/tahun Dan BEP(Q) berada pada saat produksi sebanyak 1.104.353/tahun.

\section{DAFTAR PUSTAKA}

Ibrahim, Y. 1998. Studi Kelayakan Bisnis. Rineka Cipta. Jakarta.

Kasim, S. 2004. Petunjuk Menghitung Keuntungan dan Pendapatan Usahatani. Universitas Lambung Mangkurat. Banjarmasin.

Suryana, Dr, M.Si. (2003). Kewirausahaan (Pedoman Praktis, Kiat Dan 
Proses Menuju Sukses). Jakarta. Penerbit Salemba Empat.Suliyanto, Dr. (2010). Studi Kelayakan Bisnis Pendekatan Praktis. Yogyakarta. Andi Publisher.
Rohmawati, O. 2010. Analisis kelayakan pengembangan usaha ikan nila air tawar pada Arifin Fish, Desa Ciluar, Kecamatan Bogor Utara, Kecamatan Bogor Utara, Kota Bogor. Skripsi. Institut Pertanian Bogor. 